International Journal of Biological Research, $2(2)(2014) 81-83$
International Journal of Biological Research
JPC \begin{tabular}{c} 
Journal home page: $\begin{array}{c}\text { www.sciencepubco.com/index.php/IJBR } \\
\text { do.14419/ijbr.v2i2.3163 } \\
\text { Research Paper }\end{array}$ \\
\hline
\end{tabular}

\title{
An investigation of the cause of death in Wistar rats exposed to sunlight: focus on tissue histology
}

\author{
Ayobola Abolape Iyanda, Dapo Pius Oparinde* \\ Department of Chemical Pathology, College of Health Sciences, Ladoke Akintola University of Technology, Osogbo, Nigeria \\ *Corresponding author E-mail: dpoparinde@lautech.edu.ng
}

\begin{abstract}
Objective: The aim of the study is to investigate the effects of ultraviolet rays of the sun on organs like the liver, brain, heart, kidney, lung and ileum.

Methods: Fourteen female rats ( $235 \mathrm{~g})$ were used for the study and equally distributed into 2 groups. While the rats in the test groups were left in an open place for a period of 7 hours daily for adequate exposure to sunlight, control rats were kept in cages at ambient temperature of $26^{\circ} \mathrm{C}$ in the animal house. When all the animals died on the 10th day of study, samples of different tissues were obtained, fixed in $10 \%$ neutral buffered formalin and stained with hematoxylin and eosin ( $\mathrm{H} \mathrm{\&} \mathrm{E).}$

Results: $100 \%$ mortality was recorded. Results showed no visible lesion for all the tissues of control rats whereas pathological features like severe congestion of the coronary vessel and mild pulmonary congestion as well as thickening of alveolar wall were reported for heart and lung respectively in sun-exposed rats. Moreover, in sun-exposed rats other tissues such as the brain, ileum, kidney and liver showed no visible lesion.

Conclusion: From the outcome of this study, it may be inferred that excessive sun exposure can be a cause of mortality in a nocturnal animal species, with death resulting from multi-organ damage.
\end{abstract}

Keywords: Daily Exposure, Mortality, Rat, Sunlight, Tissues.

\section{Introduction}

The Sun emits ultraviolet B (UVB) radiation $(290-315 \mathrm{~nm}$ ) that affects human health in both harmful ways such as skin cancers and beneficial ones like vitamin D3 production. The extent to which sun exposure can be linked to health has been revealed by Godar et al. (2011). These workers reported that there is an association between deficient or insufficient serum 25-hydroxyvitamin D concentrations of young Americans ( $\leq 19$ yr.) who seem inadequately exposed to sun because of sunscreen. Although there are other findings that seem to be in conflict with that, those studies indicated that people are capable of making sufficient vitamin D3 from their "casual," or every day, outdoor exposures even if they diligently use sunscreens with sun protection factor.

Barsh (2003) reported a wider role for the sun in relation to human existence. According to the results of that study while it is well known that UVB has medical effects such as synthesis of vitamin $\mathrm{D}$, it also has been linked with sunburn. In addition, as a result of its antiseptic properties it is sometimes used to sanitize tools and water. According to the author, since ultraviolet light is strongly attenuated by Earth's ozone layer, this means that the amount of UV varies greatly with latitude and has been partially responsible for many biological adaptations, including variations in human skin color in different regions of the world (Barsh, 2003).

Worldwide the incidence of skin cancer is on the increase. Some of the primary preventive activities that have been put forward by cancer agencies include protecting the skin from the sun by wearing protective clothing, using a sunscreen with appropriate sun protection factor, wearing a hat, and avoiding the sun (Stanton et al. 2004). Skin disorders are the most prominent pathological conditions associated with excessive sun exposure and abnormal skin histology has been observed in experimental animals exposed to UVB. Because these disorders are oxidative-stress mediated, abnormal histological manifestations of other tissues cannot be discounted. Therefore, the aim of this study is to examine histologic presentation of the brain, heart, lung and ileum of rats that died as a result of exposure to the sun and possibly identify the cause of death.

\section{Materials and methods}

\subsection{Care of experimental animals}

A total of 14 female Wistar rats of average weight of $235 \mathrm{~g}$ were used for the study. The animal experiment was carried out at the Experimental Animal Unit of Faculty of Veterinary Medicine, University of Ibadan, Nigeria. While the rats in the test groups were left in an open place for a period of 7 hours daily, control rats were kept in cages at average ambient temperature of $26^{\circ} \mathrm{C}$. The study took place from $8^{\text {th }}$ to $17^{\text {th }}$ February 2012 ; with the weekend of $11^{\text {th }}$ and $12^{\text {th }}$ being excluded. Seven of the rats constituted the sun-exposed group and the other seven rats served as control. Each day, exposure was for a period of 7 hours starting from 9:00 to 16:00. No form of sun-screening was employed to protect the sun-exposed group; rather they were left in an open field. The control rats were kept in cages in the animal house. All experimental animals were supplied feed and water without any form of restriction. The procedures were carried out in accordance with national and international laws and Guidelines for Care and 
Use of Laboratory Animals in Biomedical Research Institutes of Health (revised 1985).

\subsection{Histopathological examination of tissue}

Samples of liver, kidney, brain, lung, heart, kidney and ileum were obtained, and fixed in $10 \%$ neutral buffered formalin. Fixed tissues were washed overnight, dehydrated through graded alcohols and embedded in paraffin wax. Paraffin sections $5 \mu \mathrm{m}$ thick were prepared using motorized rotary microtome. After which they were stained with hematoxylin and eosin $(\mathrm{H} \& \mathrm{E})$ for the examination of tissues and cellular changes by light microscopy. Magnification was at $\times 400$.
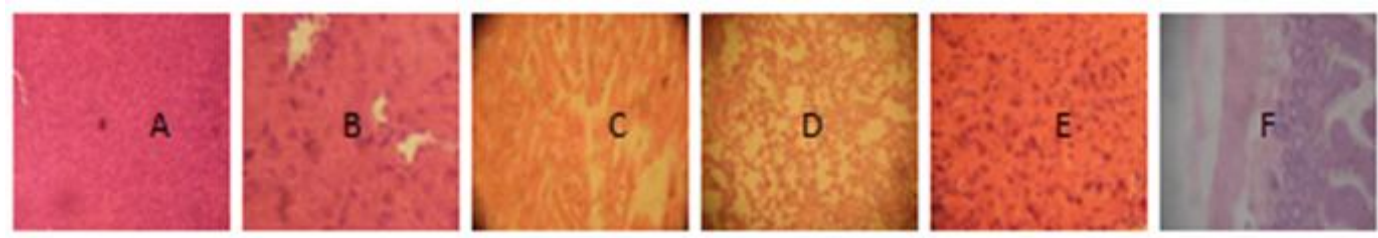

Fig. 1: The photomicrograpghs of different tissues of control rats: A- Liver (no visible lesion); B- Kidney (no visible lesion); C- heart (no visible lesion); D- lung (no visible lesion); E- brain (no visible lesion); F ileum (no visible lesion).
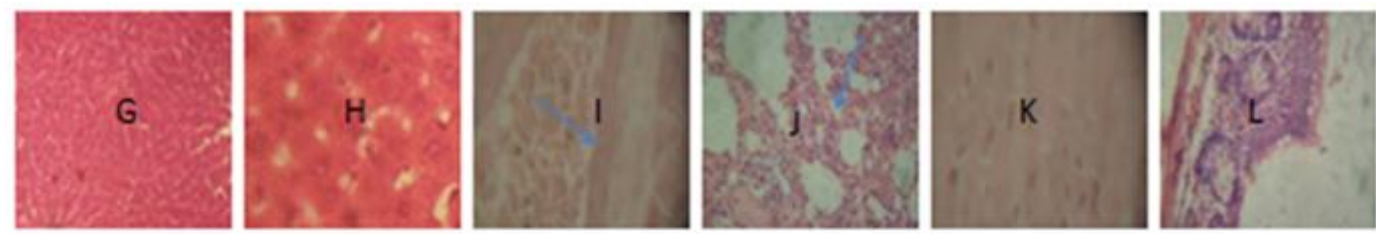

Fig. 2: The photomicrographs of different tissues of sum-exposed rates: G- liver (no visible lesion); H- (no visible lesion); I heart (severe congestion of the coronary vessel); J- Lung (mild pulmonary congestion and thickening of alveolar wall); K- brain (no visible lesion); Lileum (no visible lesion).

\section{Discussion}

Sun exposure has been linked with many physiological or pathological processes in different tissues, either through its beneficial effects via vitamin D synthesis or its free-radical generating action. The beneficial effects of the sun include prevention of bone disease in children (rickets) and adults (osteomalacia). In addition, because organs like the prostate gland, possess vitamin $\mathrm{D}$ receptor and $1 \alpha$-hydroxylase and respond to both vitamin $\mathrm{D}$ and the prohormone, the sun has been reported to play a role in the development of this tissue as well (John et al. 2005).

Sun exposure via vitamin D action also prevents prostate cancer, since there are reports that indicate that prostate cancer risk is inversely associated with sun exposure, the major source of vitamin D. According to John et al. (2005), such association is possible because $\sim 90 \%$ of circulating levels of $25-\mathrm{OHD}$ are obtained from casual sun exposure in most individuals (2003). Schwartz \& Hulka (1990) had earlier observed that the descriptive epidemiology of prostate cancer is similar with the epidemiology of adult vitamin D deficiency and proposed that vitamin D deficiency increases the risk for prostate cancer. Although John et al. (2005) confirmed that sun exposure in conjunction with vitamin $\mathrm{D}$ receptor (VDR) polymorphisms play these important roles in the etiology of prostate cancer.

Free-radical generating effect of the ultraviolet rays is well known for its role in many skin related pathological states such as both non-melanocytic skin cancer (Staples et al. 1998) and malignant melanoma (Giles \& Thursfield 1996). Moreover, ultraviolet rays have been reported to be capable of modulating the immune capability of an animal. Sun rays have also been identified for their roles in the pathogenesis of cataract, signifying the harmful effects of sun rays on the eye (WHO, 2011).

Ultraviolet B of the sun is known to be an oxidant in the nature of its action. Excessive free radical generation is known to cause oxidative deterioration of polyunsaturated fatty acids which results in the formation of hydroperoxides, short-chain aldehydes, ke- tones, and other oxygenated compounds, a process frequently called lipid peroxidation and is a common cause of cell damage or death. The histopathological features of severe congestion of the coronary vessel and thickening of alveolar wall of sun exposedrats might have also been as a result of free radical generation. Many abnormal presentations have been linked with excessive free radical generation. The abnormal histologic features of the sun-exposed rats might have played a contributory role in the $100 \%$ mortality suffered by this group of rats. That lipid peroxidation could have been a cause of the $100 \%$ mortality suffered by rats in sun exposed group can be assumed from earlier submissions. Various diseases such as atherosclerosis (Niijima et al. 2002), diabetes (Song et al. 2002), and cancer (Thirunavukkarasu et al. 2005) have been reported to be oxidative stress mediated.

In many parts of the world, exposure to sun rays, even excessive exposure cannot be avoided. This means the skin, that has been described as the organ that protects internal organs from assaults from external sources is constantly exposed to ultraviolet irradiation which increases reactive oxygen species (ROS) production and has been associated with a number of pathological alterations in the skin. Many approaches have been explored to deal with the issue of excessive sun exposure, with sun shielding techniques being very prominent but a recent photoprotection strategy that is to support the endogenous antioxidant system of the skin with natural substances through the diet or dermatological preparations has also been explored. Alpha-Lipoic acid is a substance with antioxidant properties that easily penetrates the skin as a result of its lipid soluble characteristics as well as its low molecular weight (Beitner 2003). According to Kim et al. (2011), Freisleben et al. (1994) observed that topical $\alpha$-lipoic acid cream applied to hairless mice penetrates the epidermis and is distributed in the dermis and the subcutaneous tissue after $4 \mathrm{~h}$. This revelation and the fact that enhanced protection of human cells against ultraviolet light by antioxidant combinations involving dietary carotenoids has been earlier observed are suggestive of the role of UVB on tissue damage exhibited by sun-exposed animals. 
While there is no direct contact between the sun rays and the internal organs, that the effects of the sun rays were negatively felt by many organs resulting in death of the animals can be partially explained from the fact that UVB of the sun is a known carcinogen that has been established to provoke increase free radical generation. Accumulative effect of significant changes in the antioxidant markers is capable of causing extensive alteration in histologic presentations of tissue like the heart and lung. This may also be the basis of $100 \%$ mortality observed in Wistar rats exposed for sun rays for a period of 8 days. The deaths recorded for the sun exposed rats may also be linked to the nocturnal habit of rats generally; rats are animals that are well adapted to night life, when the ray of the sun is minimal. Lack of significant amount of melanin in Wistar rats may also be responsible for the dramatic effect of sun exposure ( $100 \%$ mortality). In addition, the study was carried out in 2012, the year considered one of those years with highest intensity of sunlight in the past few decades.

\section{Conclusion}

The results of this study further portray the danger of excessive sun exposure. This study should serve as a signal to all categories of human subjects who engage in street trading especially those with low level of UV protection and high level of sun exposure of the harmful effects of sun rays. Many of whom lack adequate medical history that will enlighten them of the possibility of a genetic susceptibility to melanoma. Melanoma is a disorder that is triggered by excessive sun exposure.

\section{Acknowledgments}

We acknowledge the assistance of Mrs. V. B. Adekoya, Mr. J. O. Agbokhade and Mr. C. O. Chamuo of the Experimental Animal Unit of the Faculty of Veterinary Medicine, University of Ibadan in the care of experimental animals.

\section{Conflict of interest}

Nil.

\section{References}

[1] Barsh GS (2003) What Controls Variation in Human Skin Color? PLoS Biology 1 (1): e7. doi:10.1371/journal.pbio.0000027. http://dx.doi.org/10.1371/journal.pbio.0000027.

[2] Beitner H (2003) Randomized, placebo-controlled, double blind study on the clinical efficacy of a cream containing 5\% $\alpha$-lipoic acid related to photoageing of facial skin. British Journal Dermatology 149, 841849. http://dx.doi.org/10.1046/j.1365-2133.2003.05597.x.

[3] Freisleben HJ, Groth N, Fuchs J, Rudolph P, Zimmer G \& Herrling T (1994) Penetration of spin-labeled dihydrolipoate into the skin of hairless mice. Modification of epidermal and dermal polarity. Arzneimittelforschung 44, 1047-1050.

[4] Giles GG \& Thursfield V (1996) Trends in skin cancer in Australia. Cancer Forum 1996, 20: 188-191.

[5] Godar DE, Pope SJ, Grant WB \& Holick MF (2011) Solar UV Doses of Young Americans and Vitamin D3 Production. Environmental Health Perspective http://dx.doi.org/10.1289/ehp.1003195

[6] Holick MF (2003) Vitamin D: a millennium perspective. J Cell Biochem 88, 296-307. http://dx.doi.org/10.1002/jcb.10338.

[7] John EM, Schwartz GG, Koo J, Van Den Berg D \& Ingles SA (2005) Sun Exposure, Vitamin D Receptor Gene Polymorphisms, and Risk of Advanced Prostate Cancer. Cancer Research 65, 5470. http://dx.doi.org/10.1158/0008-5472.CAN-04-3134.

[8] Kim YM, Kim JE, Kim Y, Choi C \& Lee B (2011) Effects of $\alpha$-lipoic acid and L-carnosine supplementation on antioxidant activities and lipid profiles in rats. Nutr Res Pract 5(5), 421-428. http://dx.doi.org/10.4162/nrp.2011.5.5.421.

[9] Niijima A, Okui T, Matsumura Y, Yamano T, Tsuruoka N, Kiso Y, et al (2002) Effects of L-carnosine on renal sympathetic nerve activity and DOCA-salt hypertension in rats. Auton Neurosci 97, 99-102. http://dx.doi.org/10.1016/S1566-0702 (02)00048-6.
[10]Schwartz GG \& Hulka BS (1990) is vitamin D deficiency a risk factor for prostate cancer? [Hypothesis]. Anticancer Research 10, 1307-11.

[11]Song KH, Lee WJ, Koh JM, Kim HS, Youn JY, Park HS, et al (2005) $\alpha$-Lipoic acid prevents diabetes mellitus in diabetes-prone obese rats. Biochem Biophys Res Commun 326, 197-202. http://dx.doi.org/10.1016/j.bbrc.2004.10.213.

[12] Stanton WR, Janda M, Baade PD \& Anderson P (2004) Primary prevention of skin cancer: a review of sun protection in Australia and internationally. Health Promot Int 19 (3), 369-378. http://dx.doi.org/10.1093/heapro/dah310.

[13]Staples M, Marks R \& Giles G (1998) Trends in the incidence of nonmelanocytic skin cancer (NMSC) treated in Australia 1985-1995: are the primary prevention programs starting to have an effect? Inter $\mathrm{J}$ Cancer 78, 144-148. http://dx.doi.org/10.1002/(SICI)10970215(19981005)78:2<144::AID-IJC3>3.0.CO;2-Z.

[14] Thirunavukkarasu V, Nandhini AT \& Anuradha CV (2005) Lipoic acid prevents collagen abnormalities in tail tendon of high-fructosefed rats. Diabetes Obes Metab 2005, 7:294-297. http://dx.doi.org/10.1111/j.1463-1326.2004.00418.x.

[15] World Health Organization Ultraviolet radiation and the INTERSUN Programme: The known health effects of UV. From: http://www.who.int/uv/faq/uvhealtfac/en/index5.html Accessed: February (2011). 